\title{
Influence of the Magnetic Load on High Speed Synchronous Reluctance Machines Design
}

\author{
Gianvito Gallicchio, Marco Palmieri, Francesco Cupertino Mauro Di Nardo, Michele Degano, Chris Gerada \\ Dept. of Electrical Engineering and Information technology \\ Politecnico di Bari, Bari, Italy \\ gianvito.gallicchio@poliba.it \\ Power Electronics and Machine Control Group \\ University of Nottingham \\ Nottingham, U.K.
}

\begin{abstract}
Synchronous reluctance machines are becoming a widespread solution in many engineering areas thanks to their simple rotor structure, the absence of rare-earth permanent magnets and high efficiency. The design of such machines is a widely investigated research topic, given the challenge of analytically estimating their electromagnetic performance, especially when a high-speed scenario is considered. The design choices and assumptions, which include the selection of the magnetic load and the stator and rotor lamination materials, play an important role in the machine performance. Consequently, it is of paramount importance to assess their validity. This paper, after a brief re-call of a general design methodology able to consider all the magnetic non-linearities and structural and thermal limitations occurring at high-speed, presents a sensitivity analysis against the magnetic load when a Cobalt-based alloy is adopted for both stator and rotor laminations. The analysis is carried out for different speeds up to $90 \mathrm{krpm}$, in order to draw general design guidelines for a given outer envelope and cooling system.
\end{abstract}

Index Terms-Cobalt iron, finite element analysis, high speed, iron losses, iron ribs, magnetic load, rotor, synchronous reluctance machine, soft magnetic material.

\section{INTRODUCTION}

The revamped industrial, automotive and aerospace interests in synchronous reluctance (SyR) machines can be ascribed to its several advantages which include a noticeable volume reduction and higher efficiency if compared to induction motors [1], [2], high transient overload capability and reduced cost thanks to their passive rotor [3]. High torque ripple and low power factor constitute the most important disadvantages, which have led the main research contributions to be focused on the rotor design [4]-[7]. In particular, the influence of the number of flux barriers, their angular position at the airgap and their shape, on the average torque, power factor and torque ripple, have constituted the core topics of research [8]-[10].

Regarding the design procedure which includes both stator and rotor laminations, relevant works were reported in [11], [12]. Under certain assumptions, a set of design equations were proposed to identify the main trade-offs involved in the design stage. Such analytical methods based on the magnetic equivalent circuits have in general the clear advantage of fast prediction of the machine performance and can provide useful design guidelines. However, the hypotheses on which these models are based (including the linearity of the iron materials and the simplification of the relationship between flux and currents) could lead to imprecise performance estimation, especially when a high-speed design scenario is considered.

For these reasons, Finite Element Analysis (FEA) coupled to design optimization algorithms has been generally adopted in the literature [13]-[15] in order to fully consider all the aspects neglected in the aforementioned analytical design approach.

Despite being effective, this kind of approach can be very time-consuming according to the number of machines to be simulated. In [16] a new design procedure that joins the benefits of the analytical and FE method is introduced for low speeds SyRMs. Its extension to the high-speed scenario has been proposed in [17] where the structural and thermal limitations are also taken into account. The proposed technique, based on the design approach reported in [11], [16], simplifies the design process of a SyR machine reducing the number of independent variables to only two and considers all the electromagnetic non-linearities as well as the structural and thermal limitations affecting the machine performance. In particular, if the adoption of a retaining sleeve is avoided for sake of simplicity, the rotor integrity at high speed must be guaranteed by designing the so-called iron ribs in order to keep the rotor maximum Von Vises stress below the yield limit of the material, leading to a performance decrement (in terms of torque and power factor) caused by the saliency ratio reduction. From a thermal point of view, the rise of the iron losses due to the increasing speed pushes the designer to take into account the cooling system limitation within the design workflow. In fact, if the cooling system is preliminary chosen, the ratio between Joule and total losses has to decrease as the design speed increases in order to keep constant the total losses to be dissipated by the cooling systems. This leads to a reduction of the stator current which in turn determines a decrement of the output torque.

It is worth to underline that the conflicting requirements between the rotor structural integrity and the electromagnetic and thermal performance are greatly influenced by the selected soft magnetic materials. Indeed, in [18] a comprehensive comparative design exercise has been outlined showing the convenience of adopting Cobalt-Iron alloys only when designing SyR machines having a limited maximum speed. Above a certain speed, which depends on the geometrical and physical constraints of the design, it is more beneficial to adopt a Silicon-Iron soft magnetic material. In the low speed range, 
Co-Fe steels allow achieving better performance thanks to their higher saturation flux density compered to the $\mathrm{Si}-\mathrm{Fe}$ counterpart. As the speed increases, the lower specific iron losses of the high-performance $\mathrm{Si}$-Fe steels become more important and allow achieving higher power densities.

Beside the soft magnetic materials, the optimal machine design also depends on other preliminary design choices, such as the magnetic load (i.e the desired peak flux density in the stator yoke and teeth). The latter is usually selected as close as possible to the knee point of the B-H characteristic in order to fully exploit the adopted soft magnetic material. However, as the speed increases, designing SyR machines with a lower value of iron flux density could be beneficial given the consequent lower iron losses.

The purpose of this paper is to investigate the tradeoffs involved when selecting the iron flux density to be used during the SyR machine design when adopting a Co-Fe alloy. The study, based on the comprehensive design routine proposed in [17], examines the impact of such preliminary design choice on the optimal performance and geometries of SyR machines designed for a wide range of speeds (up to 90kprm).

Section II briefly re-calls the design routine, whereas the main results are shown in section III. Section IV reports the analysis of the final designs which leads to the main conclusions drawn in the last section.

\section{DESIGN ROUTINE DESCRIPTION}

\section{A. Design equations}

The adopted design procedure is based on the definition of two independent variables, namely the split ratio ( $s r$, airgap radius $R_{r}$ to outer radius $R_{s}$ ratio) and the magnetic ratio ( $\mathrm{mr}$, airgap flux density $B_{g}$ to iron peak flux density $B_{f e}$ ratio). If the magnetic load (i.e $B_{f e}$ ), the cooling system capability and the outer envelope (defined by $R_{s}$ and the active axial length $L$ ) are preliminary fixed, the average torque $(T)$ and the internal power factor (ipf) as well as all the geometric parameters of both stator and rotor (Fig. 1) can be expressed as function of these two variables, leading to definition of the design plane $s r-m r$, useful to easy infer the performance trends as a function of the design variables.

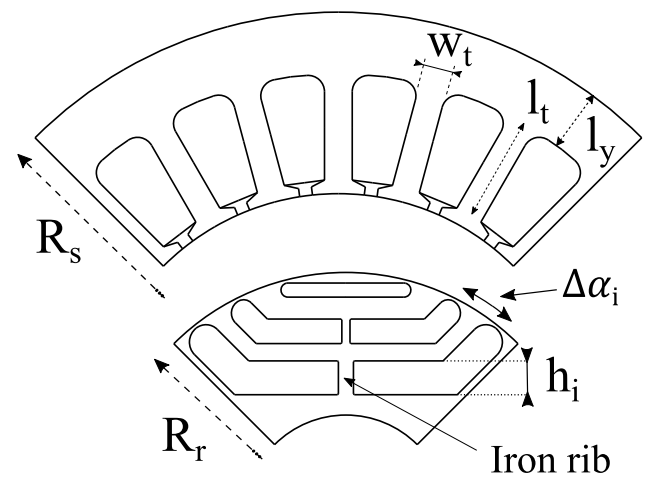

Fig. 1: Stator and rotor parametrization
The torque can be expressed as in (1) whereas the internal power factor relationship is reported in (2).

$$
\begin{gathered}
T=\frac{3}{2} p\left[\left(L_{d m} i_{d}+L_{d q} i_{q}\right) i_{q}+\right. \\
\left.-\left(L_{d q} i_{d}+\left(L_{q m}+L_{q-r i b}\right) i_{q}\right) i_{d}\right] \\
i p f=\sin (\gamma-\delta)
\end{gathered}
$$

where $L_{d m}$ and $L_{q m}$ are the d- and q-axis magnetizing inductances, $L_{d q}$ accounts for the cross-saturation effects, $L_{q-r i b}$ takes into account the flux short-circuited by the structural iron ribs (negligible at low speed), $i_{d}$ and $i_{q}$ are the d- and q-axis currents, $p$ is the number of pole pairs and $\gamma$ and $\delta$ are the current and flux phase angles respectively. By defining the d-axis flux per pole $\left(2 \cdot R_{r} \cdot L \cdot B_{g}\right)$, the stator tooth and yoke thicknesses $\left(w_{t}, l_{y}\right)$ can be calculated imposing the desired iron flux density $B_{f e}$ :

$$
\begin{aligned}
l_{y} & =\frac{\pi}{2} \frac{R_{s}}{p} s r \cdot m r \\
w_{t} & =\frac{2 \pi R_{s}}{6 q p} s r \cdot m r
\end{aligned}
$$

where $q$ is the number of slots per pole per phase. Furthermore, if a uniform distribution of the equivalent rotor slots is considered and imposing barriers sharing the same permeance, the rotor can be fully defined [12].

From (1) and (2) it follows that the proper calculation of torque and power factor clearly depends on the accuracy of the magnetic model estimation. Both $\mathrm{d}$ - and q-axis magnetizing inductances can be determined and expressed as function of $s r$ and $m r$ adopting the simplified formulation reported in [12] which neglects both saturation and cross-saturation of the soft magnetic materials. The rib inductance $\left(L_{q-r i b}\right)$, due to the flux short-circuited by the structural iron ribs (the radial and the tangential ones), is dependent by the ribs dimension. If the tangential iron ribs are fixed to the mechanical tolerance, the calculation of the radial ribs width $w_{r}(i)$ is carried out adopting the simplified analytical formulation which considers only the steady state centrifugal force $F_{c}(i)$ acting on the $i^{t h}$ flux guide [13], [19]:

$$
w_{r}(i)=\frac{k_{s f} F_{c}(i)}{\sigma_{\max } L}
$$

where $k_{s f}$ is a safety factor (usually between 1.5 and 3.5) and $\sigma_{\max }$ is the yield strength of the rotor material. The centrifugal force is proportional to the square of the rotational speed, therefore also the width of the structural iron bridges will rise with the square of the speed. Once the ribs dimension has been calculated, $L_{q-r i b}$ is computed using a simplified formulation which considers all the ribs equally saturated [16], [17].

The d-axis current can be deduced by the Ampère's law [17], whereas the q-axis one is calculated by knowing the maximum current $I_{\max }$. The latter can be computed in several ways, according to the criterion selected for the whole design 
plane (i.e constant current density, constant Joule losses, constant total losses, etc.). Since the aim of this work is to make a fair comparison between machines designed for different speeds, the constant total losses criterion is hereafter adopted. In fact, adopting such criterion leads to machines sharing a similar thermal behaviour and so the cooling system could be chosen whatever speed is selected. In particular, once the ratio $k_{j}$ between the total losses and the stator external surface is defined, the current $I_{\max }$ is calculated using (6):

$$
I_{\text {max }}=\frac{1}{3 N_{s}} \sqrt{\frac{k_{f i l l} A_{\text {slots }}}{2 \rho_{c u}\left(L+L_{\text {ew }}\right)}\left(2 \pi R_{s} L k_{j}-P_{f e}\right)}
$$

where $N_{s}$ is the number of turns in series, $k_{f i l l}, A_{\text {slots }}$ and $L_{e w}$ are the slot filling factor, area and end-winding length respectively, $\rho_{c u}$ is the copper resistivity and $P_{f e}$ are the stator iron losses. The latter are estimated using the modified Steinmetz's equation:

$$
P_{f e}=M_{f e}\left[k_{h} f^{\alpha} B_{f e}^{\beta}+k_{e}\left(f B_{f e}\right)^{2}\right]
$$

where $M_{f e}$ is the iron mass, $k_{h}, k_{e}, \alpha$ and $\beta$ are coefficients related to the considered magnetic material, and $f$ is the electrical frequency.

From eq. (6) and (7) it is clear that as the speed increases, the rise of the stator iron losses reduces the maximum current and consequently the average torque In addition, it can be deduced that the choice of $B_{f e}$ is not univocal. In fact, a lower value of $B_{f e}$ leads to a lower reduction of the maximum current at the cost of a worse exploitation of the soft magnetic material. When designing low speed machines, $B_{f e}$ should be selected close to the knee value of $B-H$ characteristic since the iron losses are negligible. Conversely, as the speed increases, the iron losses play a more important role and the trade-off between the need of having an optimal exploitation of the soft magnetic material and the need of reducing the iron losses, could lead to the definition of a threshold speed above which the reduction of $B_{f e}$ improves the machine performance.

\section{B. Improving the magnetic model}

The described design procedure presents limits due to strong approximations which include the linearization of the soft magnetic materials (saturation and cross saturation are not considered), the simplification of the loss model (which does not include the harmonic losses) and the rude estimation of the q-axis inductance due to the structural iron bridges.

In order to improve the performance estimation without sacrificing the fast performance evaluation of the described analytical approach, a hybrid design procedure has been proposed in [17] for high-speed SyR machines and here is briefly re-called. The methodology consists of FE simulating only few machines of the overall design plane (e.g. the ones at the corners) in order to compute the $\mathrm{d}$ - and q- axis inductances (magnetizing and leakage components) using the frozen permeability method. From the field solution, also the

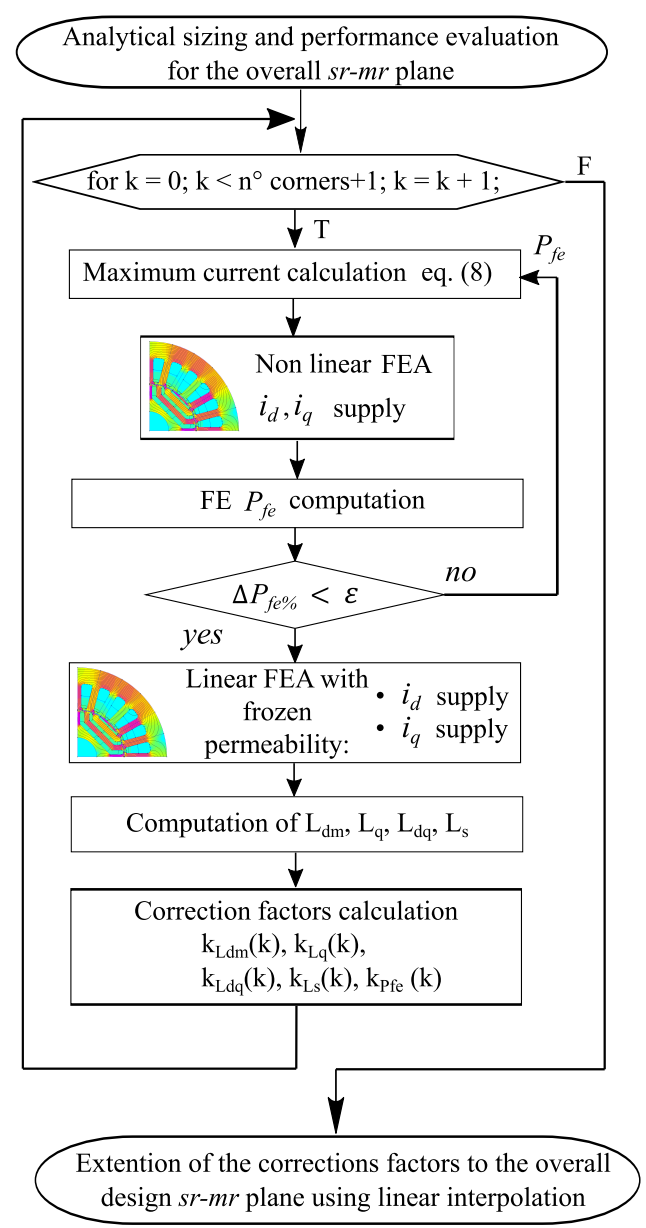

Fig. 2: Flowchart of the hybrid procedure.

actual stator iron losses are computed and used to update the maximum current (eq. 6) within an iterative procedure.

5 corrections factors (i.e the ratio between the FE computed quantity and the analytical one), are computed for each FEsimulated machine. These correction factors are then extended to the overall design plane $s r-m r$ using a linear interpolation, allowing the magnetic model adjustment [17]. For the sake of clarity, Fig. 2 reports the flowchart of the hybrid procedure.
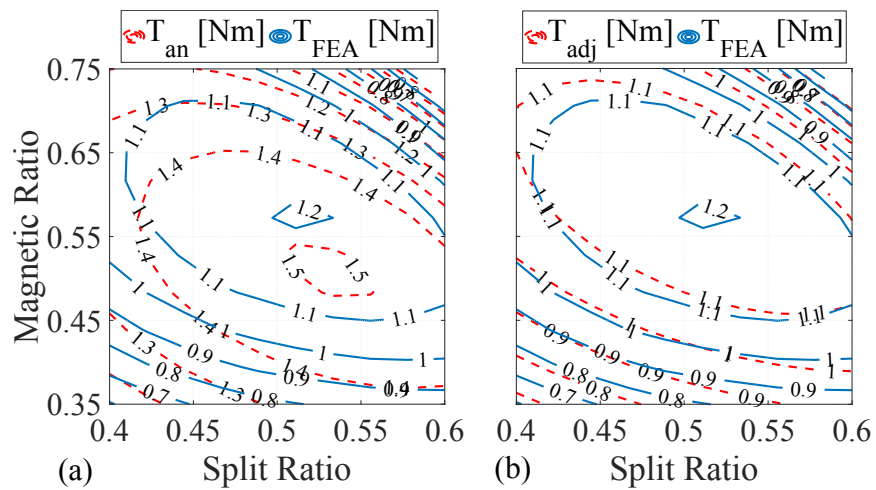

Fig. 3: Comparison between analytical and FE computed torque before (a) and after (b) the magnetic model adjustment. 
TABLE I: Initial geometrical constraints and preliminary design assumptions

\begin{tabular}{c||cc}
\multicolumn{1}{c||}{ Parameter } & Value & Units \\
\hline \hline External radius & 30 & $\mathrm{~mm}$ \\
\hline Stack length & 30 & $\mathrm{~mm}$ \\
\hline Pole pair & 2 & $/$ \\
\hline Barrier angle at the airgap & $16.87,28.12,39.38$ & $\mathrm{deg}$. \\
\hline Cooling capability & 50000 & $\mathrm{~W} / \mathrm{m}^{2}$ \\
\hline Stator yoke flux density & $1.2-1.8$ & $\mathrm{~T}$ \\
\hline Stator tooth flux density & $1.55-2.25$ & $\mathrm{~T}$ \\
\hline Airgap thickness & 0.25 & $\mathrm{~mm}$ \\
\hline Stator/Rotor material & Hiperco 50A/Hiperco HS & $/ /$ \\
\hline
\end{tabular}

Fig. 3a shows the comparison between the analytical and FE computed torque at $50 \mathrm{krpm}$ without magnetic model adjustment of a set of SyR machines whose main dimensions are reported in Table I. Fig. 3b shows the same comparison after the application of the correction procedure. The proposed hybrid design procedure allows obtaining an excellent agreement between the analytically adjusted and FE-computed torque contours.

\section{RESULTS}

The described hybrid design procedure, being computationally not expensive, can be applied to investigate the the torque and power capability of SyR machines as a function of the rotational speed considering thermal and structural limitations. The initial geometrical constraints and preliminary design assumptions are reported in Table I. The stator and rotor laminations are composed by $\mathrm{CoFe}$ alloys namely Hiperco 50A and Hiperco 50HS, respectively. The former presents excellent magnetic performance, whereas the latter features high yield strength due to the different annealing process.

With the aim of maximizing the power capability the procedure is applied for several speeds from $1 \mathrm{krpm}$ to 90 $\mathrm{krpm}$ and for four different values of the magnetic load $B_{f e}$, which determines the working point of the stator yoke and teeth. The B-H curve of the stator lamination steel is reported in Fig. 4, along with four markers highlighting the considered working points of the stator yoke.

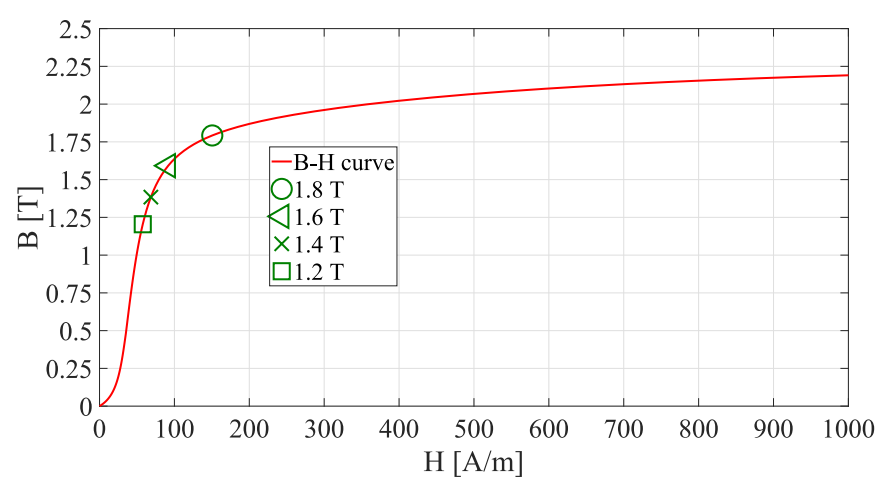

Fig. 4: BH characteristic of Hiperco 50A.
Torque and power factor contours for each speed are then calculated in their respective $s r-m r$ plane. From the latter, the maximum torque design is chosen in order to evaluate the maximum power capability as a function of the speed and the selected magnetic load. It is worth to underline that different speeds and/or different magnetic loads could lead to different locations of the maximum torque designs in the $s r-m r$ plane and so different geometries as well. Indeed, the combination $s r-m r$ which maximizes the torque at low speed does not necessarily coincide with the one maximizing the torque at high speed. This is due to the different effect of the iron losses, when choosing a different magnetic load, on the torque contours and so on the maximum torque design.

Fig. 5a and $5 \mathrm{~b}$ reports the maximum torque and the internal power factor of the maximum torque designs as a function of the speed for four different magnetic loads: $1.8 \mathrm{~T}, 1.6$ $\mathrm{T}$, $1.4 \mathrm{~T}$ and $1.2 \mathrm{~T}$, whereas the output power is reported in Fig. 6. As expected, the structural and thermal limiting factors negatively affect both torque and internal power factor, whatever magnetic load is chosen. It is worth to underline that the higher value of $B_{f e}$ provides the best performance (torque wise) up to $60 \mathrm{krpm}$. Above this speed, reducing the magnetic load to $1.6 \mathrm{~T}$ at $70 \mathrm{krpm}, 1.4 \mathrm{~T}$ at $80 \mathrm{krpm}$ and $1.2 \mathrm{~T}$ at $90 \mathrm{krpm}$ clearly leads to a performance improvement. In other words, each case features a threshold speed above which it is not convenient to further increase the speed, since the output power will decrease. This threshold speed can be increased

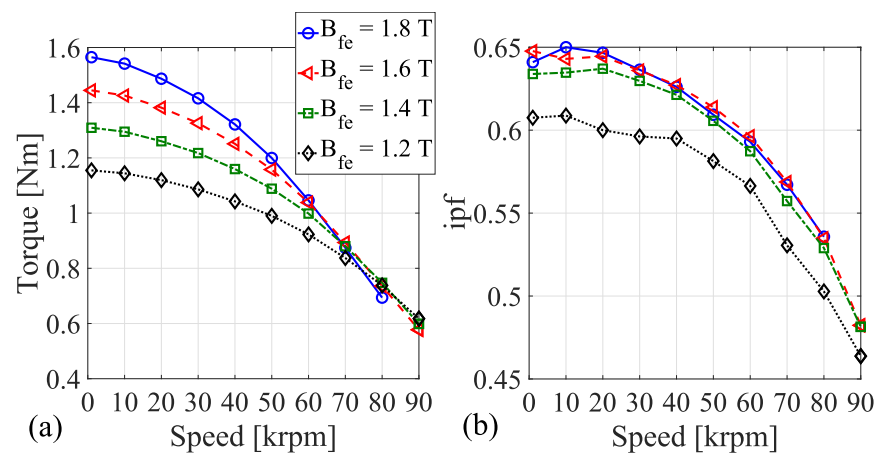

Fig. 5: Torque (a) and ipf (b) as function of the speed

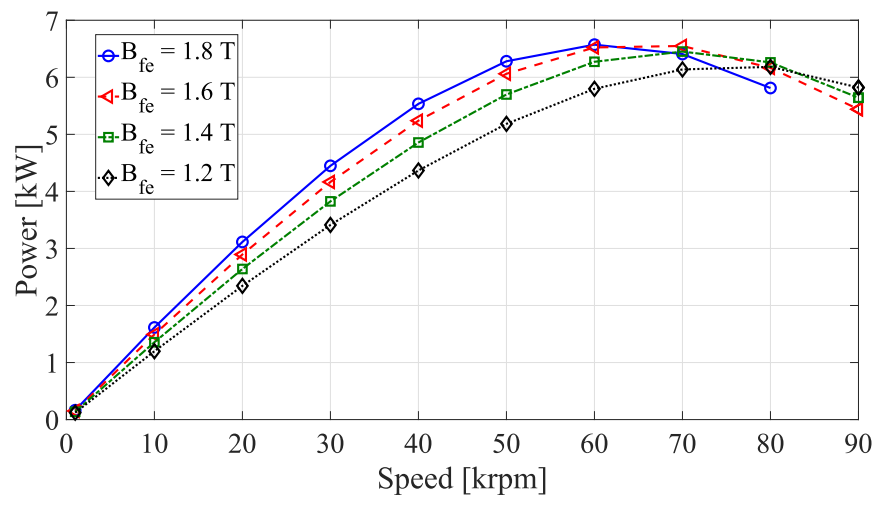

Fig. 6: Power as function of the speed 
by reducing the magnetic load as shown in Fig. 6 although it comes at the cost of a slightly lower maximum power.

The reason of this behavior can be inferred analysing Fig. 7 and 8 . The first one reports the $\mathrm{d}$ - and $\mathrm{q}$-axis currents and the iron losses of the optimal designs as function of both speed and magnetic load while the second shows the d- and q-axis inductances and their difference.

Clearly, the rise of the iron losses is more pronounced when adopting a high magnetic load. As an example, at $80 \mathrm{krpm}$ the stator iron losses are $160 \mathrm{~W}$ when $B_{f e}=1.8 T$ and $120 \mathrm{~W}$ when $B_{f e}=1.2 T$. As a consequence, in the first case the q-axis current reduction is higher with respect to the latter case. Regarding the d-axis current, high iron flux densities obviously require higher magnetizing currents; the reduction of this current components with the speeds is mainly ascribed to the different location of the maximum torque design in the $s r-m r$ plane.

As expected, the d-axis inductance is almost independent from the speed and increases as the iron flux density decreases (up to a certain point until the unsaturated value is reached). The q-axis inductance drastically increases with the speed due to the increment of the iron bridge dimension. It also increases as iron flux density decreases due to the higher ribs-shunted fluxes. The trends of both inductances make their difference decrease with the speed and improve with lower magnetic loads.

Before 60krpm, adopting a high value of iron flux density is beneficial since the influence of the current reduction due to the iron losses is not a preponderant phenomenon in the torque generation. Conversely, as the speed increases, the qaxis current reduction is more pronounced so it is preferable to select a lower iron flux density which also allow a higher inductances difference.

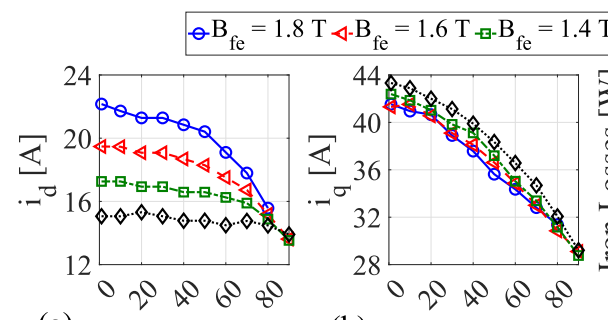

(a) Speed [krpm] (b) Speed [krpm]

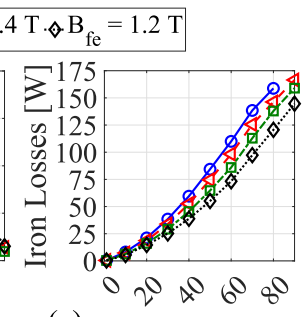

(c) Speed $[\mathrm{krpm}]$
Fig. 7: d-axis current $i_{d}$ (a), q-axis current $i_{q}$ (b) stator iron losses (c) at the maximum torque as function of the speed

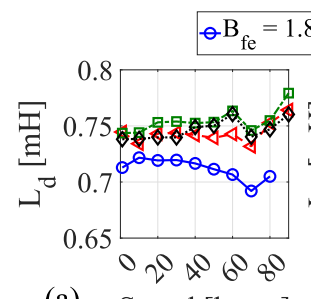

(a) Speed [krpm]

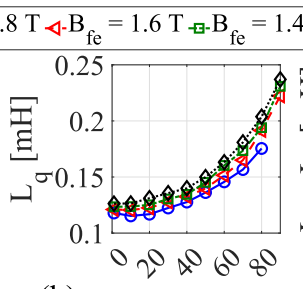

(b) Speed $[\mathrm{krpm}]$

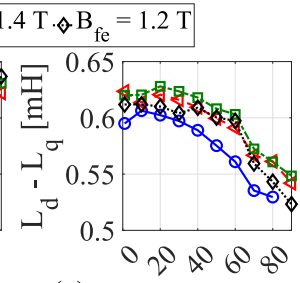

(c) Speed $[\mathrm{krpm}]$
Fig. 8: $L_{d}$ (a), $L_{q}$ (b) and $L_{d}-L_{q}$ (c) at the maximum torque as function of the speed.
Regarding the internal power factor of the maximum torque designs, it always increases with the magnetic load even after $60 \mathrm{krpm}$ as shown in Fig. 5b. This is clearly due to the lower rib-shunted fluxes ascribed to the higher iron flux density.

\section{Optimal Machines}

The design variables (split and magnetic ratio, $s r-m r$ ) of the optimal (torque wise) design are shown in Fig. 9 while the cross sections of the optimal geometries at three different speeds (20, 50 and $80 \mathrm{krpm})$ and their flux density maps are shown in Fig. 10. Fig. 10a, 10b and 10c report the optimal machines obtained considering the lowest magnetic load (i.e $1.2 \mathrm{~T}$ ), whereas the highest magnetic load case (i.e $1.8 \mathrm{~T}$ ) cross-sections are reported in Fig. 10d, 10e and 10f. Table II reports torque, iron losses, rotor radius, tooth and back iron thickness of the considered optimal machines.

Analysing both Fig. 9 and 10 and Table II, the following considerations can be drawn.

- The rotor radius is slightly affected by the speed (up to $60 \mathrm{krpm}$ ) whatever the magnetic load is imposed and slightly decreases as the iron flux density decreases.

- The optimal magnetic ratio decreases with the speed and with high value of iron flux density.
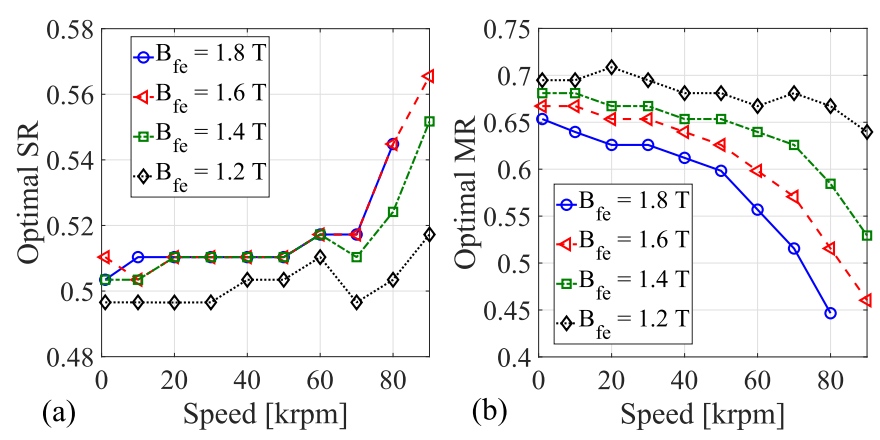

Fig. 9: Optimal (torque wise) design variables $s r$ (a) and $m r$ (b) as function of the speed

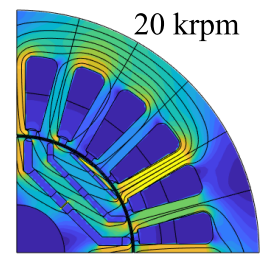

(a)

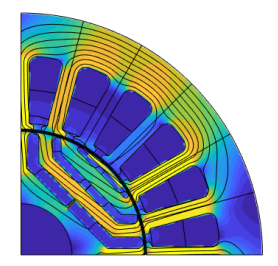

(d)

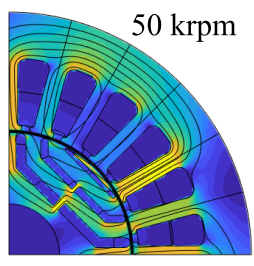

(b)

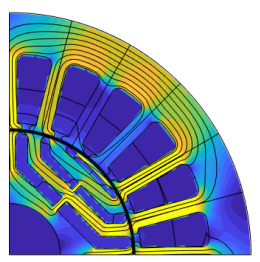

(e)

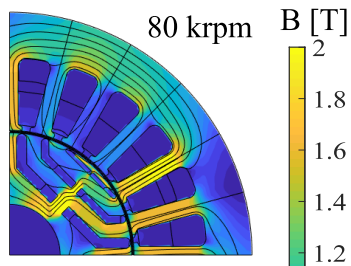

(c)

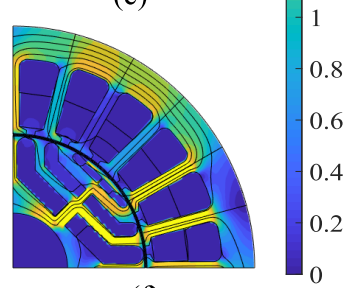

(f)

Fig. 10: Cross sections of the optimal machines at (a,d) 20krpm, $(\mathrm{b}, \mathrm{e}) 50 \mathrm{krpm},(\mathrm{c}, \mathrm{f}) 80 \mathrm{krpm}$, considering a magnetic load equal to $(\mathrm{a}, \mathrm{b}, \mathrm{c}) 1.2 \mathrm{~T}$ and $(\mathrm{d}, \mathrm{e}, \mathrm{f}) 1.8 \mathrm{~T}$ 
TABLE II: Comparison between optimal machines

\begin{tabular}{|c|c|c|c|}
\hline Speed & Variable & $\mathrm{B}_{\mathrm{fe}}=1.2 \mathrm{~T}$ & $\mathrm{~B}_{\mathrm{fe}}=1.8 \mathrm{~T}$ \\
\hline \multirow{5}{*}{20 krpm } & $T[\mathrm{Nm}]$ & 1.10 & 1.49 \\
\hline & $P_{f e-s t}[W]$ & 15 & 21 \\
\hline & $R_{r}[m m]$ & 14.3 & 15.3 \\
\hline & $l_{y}[m m]$ & 5.6 & 5.31 \\
\hline & $w_{t}[m m]$ & 2.11 & 2.01 \\
\hline \multirow{5}{*}{50 krpm } & $T[N m]$ & 0.98 & 1.20 \\
\hline & $P_{f e-s t}[W]$ & 55 & 84 \\
\hline & $R_{r}[m m]$ & 15.1 & 15.3 \\
\hline & $l_{y}[m m]$ & 5.7 & 5.07 \\
\hline & $w_{t}[m m]$ & 2.15 & 1.92 \\
\hline \multirow{5}{*}{80 krpm } & $T[N m]$ & 0.74 & 0.68 \\
\hline & $P_{f e-s t}[W]$ & 120 & 160 \\
\hline & $R_{r}[m m]$ & 15.1 & 16.3 \\
\hline & $l_{y}[\mathrm{~mm}]$ & 5.6 & 4.04 \\
\hline & $w_{t}[\mathrm{~mm}]$ & 2.11 & 1.52 \\
\hline
\end{tabular}

- The relationship between the stator tooth thickness $\left(w_{t}\right)$ and the speed is dependent by the selected iron flux density. When the latter is small, $w_{t}$ remains almost constant, whereas it decreases for higher $B_{f e}$ values. The same considerations can be extended to the stator yoke thickness $\left(l_{y}\right)$.

- The flux density contour plots highlight the accuracy of the hybrid analytical design approach, since the actual value of the iron flux density is on average equal to the one imposed during the design exercise.

\section{CONCLUSION}

In this paper, the influence of the magnetic load in the design of synchronous reluctance machines has been investigated for a wide range of maximum operating speeds. The design has been performed fixing the outer envelope, with a constant loss design scenario and considering different structural rotor design as the rotational speed increases. High performing CobaltIron alloys have been considered for both stator and rotor laminations in order to assess the effect of the magnetic load on both optimal machine geometries and related performance.

It has been found that the magnetic exploitation of the lamination materials has to be selected according to the maximum operating speed of the machine.

Indeed, when designing machines in the low-medium speed range, the optimal performance are obtained when selecting the magnetic load close to the knee point of the material $B-$ $H$ characteristic. At low speeds, the iron losses influence on the overall losses is negligible and it is more convenient to maximize the magnetic load in order to increase the saliency ratio.

On the contrary, when designing high speed SyR machines, it is better to reduce the magnetic exploitation of the adopted soft magnetic materials. In fact, the rate of the torque decrement associated with the maximum current reduction (needed to keep constant the overall losses) is higher than the rate of the torque decrement due to the saliency ratio reduction (associated with the lower magnetic load).

\section{REFERENCES}

[1] A. T. de Almeida, F. J. T. E. Ferreira, and G. Baoming. Beyond induction motors-technology trends to move up efficiency. IEEE Transactions on Industry Applications, 50(3):2103-2114, May 2014.

[2] K. Lang, A. Muetze, R. Bauer, and S. Pircher. Comparison of induction and synchronous reluctance machine based actuators for elevated temperature environments. IEEE Transactions on Energy Conversion, 31(3):1012-1022, 2016

[3] M. Palmieri, G. L. Cascella, and F. Cupertino. Design methodologies for the output power maximisation of synchronous reluctance machines. IET Electric Power Applications, 13(8):1131-1140, 2019.

[4] R. Moghaddam, F. Magnussen, and C. Sadarangani. Novel rotor design optimization of synchronous reluctance machine for low torque ripple. In 2012 XXth International Conference on Electrical Machines, pages 720-724, 2012.

[5] M. Sanada, K. Hiramoto, S. Morimoto, and Y. Takeda. Torque ripple improvement for synchronous reluctance motor using an asymmetric flux barrier arrangement. IEEE Transactions on Industry Applications, 40(4):1076-1082, 2004.

[6] J. H. Lee. Optimum design criteria for maximum torque density and minimum torque ripple of synrm according to the rated wattage using response surface methodology. IEEE Transactions on Magnetics, 45(3):1578-1581, 2009.

[7] E. Howard, M. J. Kamper, and S. Gerber. Asymmetric flux barrier and skew design optimization of reluctance synchronous machines. IEEE Transactions on Industry Applications, 51(5):3751-3760, 2015.

[8] N. Bianchi. Synchronous reluctance and interior permanent magnet motors. In Electrical Machines Design Control and Diagnosis (WEMDCD), 2013 IEEE Workshop on, pages 75-84.

[9] D.A. Staton, T.J.E. Miller, and S.E. Wood. Maximising the saliency ratio of the synchronous reluctance motor. Electric Power Applications, IEE Proceedings B, 140(4):249-259, July 1993.

[10] Oguz Korman, Michele Degano, Mauro Di Nardo, and Chris Gerada. A novel flux barrier parametrization for synchronous reluctance machines. IEEE Transactions on Energy Conversion, pages 1-1, 2021.

[11] A. Vagati. The synchronous reluctance solution: a new alternative in ac drives. In Industrial Electronics, Control and Instrumentation, 1994 IECON '94., 20th Int. Conference on, volume 1, pages 1-13 vol.1, 1994.

[12] A. Vagati, G. Franceschini, I. Marongiu, and G. P. Troglia. Design criteria of high performance synchronous reluctance motors. In Industry Applications Society Annual Meeting, 1992., Conference Record of the 1992 IEEE, pages 66-73 vol.1.

[13] C. Babetto, G. Bacco, and N. Bianchi. Synchronous reluctance machine optimization for high-speed applications. IEEE Transactions on Energy Conversion, 33(3):1266-1273, 2018.

[14] Andrea Credo, Giuseppe Fabri, Marco Villani, and Mircea Popescu. A robust design methodology for synchronous reluctance motors. IEEE Transactions on Energy Conversion, 35(4):2095-2105, 2020.

[15] M. Palmieri, M. Perta, and F. Cupertino. Design of a 50.000-r/min synchronous reluctance machine for an aeronautic diesel engine compressor. IEEE Transactions on Industry Applications, 52(5):3831-3838, Sept 2016.

[16] S. Ferrari and G. Pellegrino. Feafix: Fea refinement of design equations for synchronous reluctance machines. IEEE Transactions on Industry Applications, 56(1):256-266, 2020

[17] G. Gallicchio, M. Di Nardo, M. Palmieri, A. Marfoli, M. Degano, C. Gerada, and F. Cupertino. High speed synchronous reluctance machines: Modeling, design and limits. IEEE Transactions on Energy Conversion, pages 1-1, 2021.

[18] M. Di Nardo, G. Gallicchio, M. Palmieri, A. Marfoli, G. Lo Calzo, M. Degano, C. Gerada, and F. Cupertino. High speed synchronous reluctance machines: Materials selection and performance boundaries IEEE Transactions on Transportation Electrification, pages 1-1, 2021.

[19] M. Palmieri, M. Perta, F. Cupertino, and G. Pellegrino. High-speed scalability of synchronous reluctance machines considering different lamination materials. In IECON 2014 - 40th Annual Conference of the IEEE Industrial Electronics Society, pages 614-620, 2014. 